\title{
CAMBIASSU

Demandas de representação e comunicação no Facebook: análise de fanpages de organizações
indigenistas $^{1}$

Representative claims and communication on Facebook: indigenists organizations fan pages analysis

\section{Thiago Almeida Barros}

Professor Adjunto do curso de Comunicação Social da Universidade da Amazônia. Bacharel em Comunicação Social Jornalismo (UFPA). Mestre em Planejamento do Desenvolvimento Sustentável (NAEA-UFPA). Doutorando em Comunicação, Linquagens e Cultura (PPGCLC-UNAMA). E-mail: tbarros8largmail.com.

\footnotetext{
1 Este artigo é uma versão atualizada de trabalho publicado nos anais do $41^{\circ}$ Congresso Brasileiro de Ciências da Comunicação. ISSN: $2175-4683$.
} 


\section{Analaura Corradi}

Professora Titular do Programa de Pós-Graduação em Comunicação, Linguagens e Cultura (PPGCLC) da Universidade da Amazônia (UNAMA). Doutora em Ciências Agrárias - Ecossistema Amazônia (UFRA). E-mail: corradi7@igmail.com.

\section{Gecilene Magalhães Marinho Barros}

Coordenadora Pedagógica (SEDUC-PA). Pedagoga (UEPA) e Bacharel em Comunicação Social (UNAMA). Mestra em Comunicação, Linquagens e Cultura (PPGCLC) da Universidade da Amazônia (UNAMA). E-mail: gecilene.marinho@rgmail.com. 


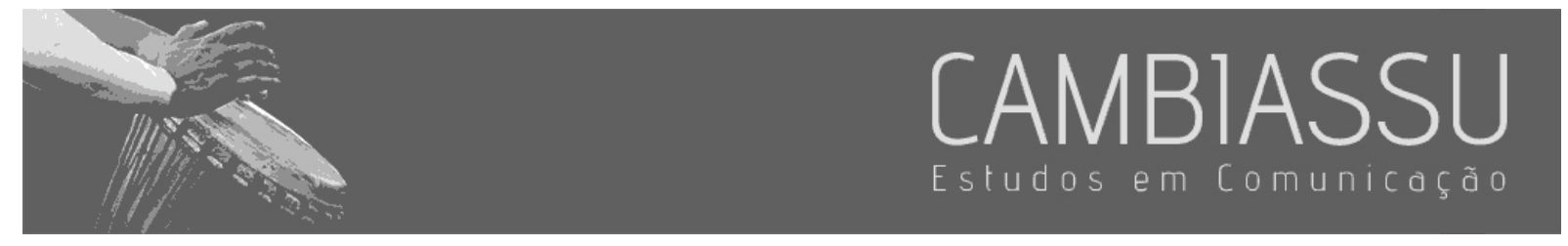

\section{Resumo}

Este artigo consiste em análise de conteúdo das fanpages das organizações Mobilização Nacional Indígena e Conselho Indigenista Missionário na rede social Facebook, entre agosto e novembro de 2017, considerando a proposta dos elementos de cultura de comunicação on-line de Kavada (2013) e identificação de demandas de representação (representative claim) segundo Saward (2010). Os resultados indicam que as organizações levantam demandas semelhantes, como a demarcação de terras indígenas, mas têm diferenças em relação à abordagem dos conteúdos, fins e funções da comunicação, o que abre espaço para problemas quanto à representação política não eleitoral de povos indígenas.

Palavras-chave: movimento indígena. Facebook. representação política. cultura de comunicação.

\section{Abstract}

This article consists of content analysis of the fan pages of the organizations Mobilização Nacional Indígena and Conselho Indigenista Missionário on the Facebook, between August and November 2017, considering the proposal of the elements of Kavada's online communication culture (2013) and identification of representative claims (SAWARD, 2010). The results indicate that the organizations raise similar demands, such as the demarcation of indigenous lands, but have differences in relation to the approach to the contents and purposes and functions of communication, which opens space for problems regarding the non-electoral political representation of indigenous peoples.

Keywords: indigenous movement. Facebook. political representation. communication culture. 


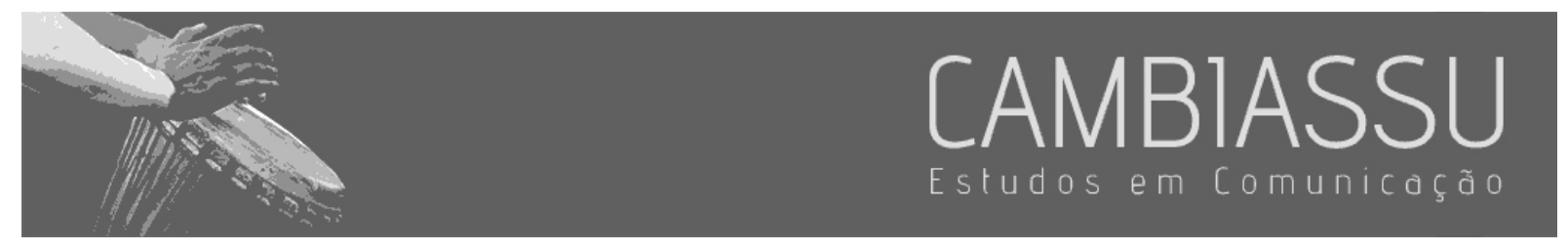

\section{Movimentos sociais, redes e estratégias de visibilidade}

No momento em que povos indígenas, afetados pela expansão das fronteiras de desenvolvimento e grandes projetos no Brasil, não conseguem dialogar com a sociedade sobre os impactos previstos ou já sofridos a partir da mediação jornalística ou de instrumentos de consulta legais, como as audiências públicas, o uso da internet e das redes sociais se apresenta como uma solução tanto para a comunicação quanto como possibilidade de organização e ampliação das ações de movimentos sociais indígenas.

Quando as ações são ampliadas no campo da internet, o movimento se enquadra em uma nova configuração, em formato de rede, em busca de um espaço de autonomia que não seja controlado por governos e empresas. Nesse percurso, podem "articular mentes, criar significado, contestar o poder" (CASTELLS, 2013, p. 7). Nesse sentido, redes sociais como o Facebook abrigam inúmeros perfis relacionados à temática ou fanpages de associações comandadas por indígenas e organizações não-governamentais (ONGs) que atuam como parceiros na divulgação de questões importantes.

Grupos de pressão, que antes se concentravam em táticas, como mobilizações e protestos, se utilizam das possibilidades oferecidas pela internet e redes sociais para uma nova formatação dos movimentos sociais - e, consequentemente, das estratégias e dinâmicas para obtenção de visibilidade na esfera pública e possível intervenção no processo de políticas públicas. Maia (2008, p. 330) aponta que a internet é o ambiente que possibilita interconexão e interações e "[...] se distingue da comunicação produzida pelos meios de comunicação convencionais por permitir que qualquer sujeito possa tornar-se emissor [...] produzindo informação ou repassando-a a outro".

Castells (2015) afirma que o processo de comunicação interativa tem potencial para alcançar audiências de massa, mas não funciona como "antídoto real" contra a interferência de grupos políticos e econômicos na mídia e outras esferas porque também está suscetível à mesma operacionalização. O ponto positivo é que modificou as práticas de poder. Ele defende a existência de uma interação entre 


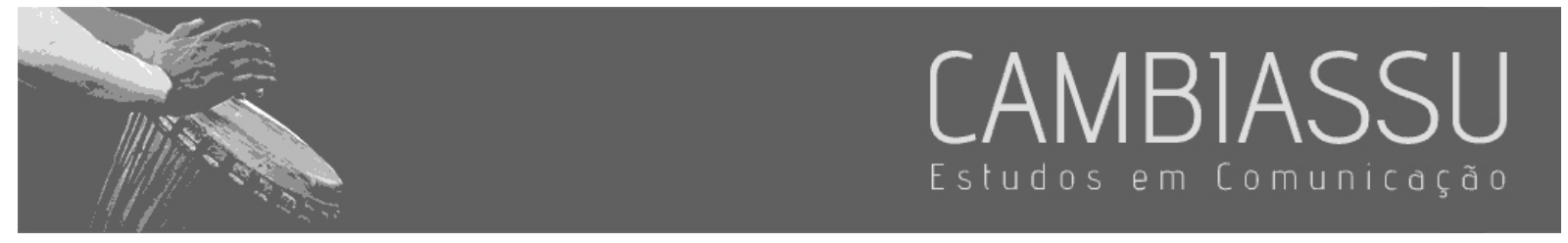

"poder", oriundo das instituições, e "contrapoder", vindo da sociedade civil. As novas formas e processos de comunicação, argumenta, "são decisivos em reestruturar essa relação". A tecnologia "maximiza" as possibilidades de expressão e mobilização de ações sociais que desafiam as autoridades (CASTELLS, 2015, p. 34-35).

Movimentos sociais ou ONGs que as apoiam em campanhas específicas recorrem à mídia em busca de visibilidade, porque, segundo Mendonça (2011, p. 18), “[...] precisam estabelecer interlocuções com outros setores da sociedade e com os atores do sistema político para tematizar suas questões". Ele reforça: para que os argumentos dos grupos se tornem visíveis, eles precisam desenvolver estratégias com quadros de interpretação culturalmente disponíveis.

Na visão de Gomes (2014), redes sociais são caixas de ressonância de questões sociais que, inclusive, conseguem atrair a atenção dos meios de comunicação de massa, do público desses meios, dos poderes Executivo, Legislativo e Judiciário, etc. A partir da revolução de 2010, quando a internet migrou definitivamente para dispositivos móveis, as redes se tornaram rápidos instrumentos de atualização social. Para ele, em breve a população será composta em maioria por nativos digitais, o "[...] que parece indicar que estamos rumando para uma civilização de hiperconectados, com todas as consequências que isto comporta." (GOMES, 2014, p. 26).

Apesar da ampliação do número de organizações representativas de povos indígenas, grupos se apresentam como porta-vozes e catalisadores de demandas, em relações que podem ser classificadas como estratégias de representação política não eleitoral. Nesse processo, que envolve expertises específicas para a atuação em redes sociais, essas organizações reforçam relações de advocacy — procedimento ligado à promoção, defesa ou argumentação de uma causa ou demanda — com o objetivo de que as ações políticas sejam mais efetivas, adequando-as à necessidade de modulação de fala para sustentar debates públicos (SAWARD, 2010). 


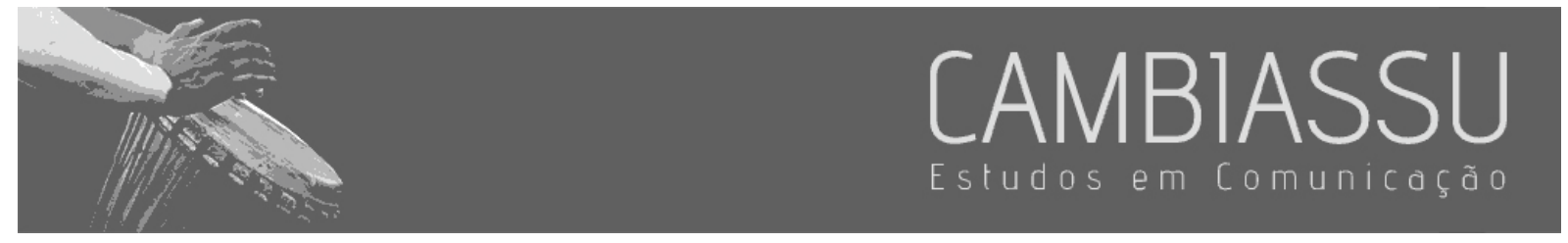

Nesse contexto, este artigo tem como objetivo compreender como grupos distintos apresentam demandas de atores e organizações indígenas a partir do uso de redes sociais como ferramentas de visibilidade. Para isso, analisamos o conteúdo das fanpages da Mobilização Nacional Indígena (MNI), organização comandada por indígenas de etnias de todas as regiões do País, e do Conselho Indigenista Missionário (CIMI), organização de base religiosa, braço da Confederação Nacional dos Bispos do Brasil (CNBB), que atua como porta-voz de movimentos sociais desde os anos 1970.

\section{Representação política não eleitoral e advocacy}

A separação entre governantes e governados gera impactos na reprodução das desigualdades sociais, aponta Miguel (2014). Nesse contexto, minorias sexuais, grupos de trabalhadores e minorias étnicas tendem a ser sub-representados. A condição de representante, no entanto, pode abrir espaço para a elaboração de novos interesses, diferentes das demandas do grupo representado. Miguel (2014, p. 17) levanta essas questões para esclarecer que a dinâmica da representação política está ligada a diferentes assimetrias presentes nas relações sociais.

Miguel (2014) reforça que a compreensão sobre o conceito de representação política sofre impactos por conta da carga polissêmica da palavra "representar": uma atriz pode representar sua personagem, um advogado representa seu cliente perante à banca, um quadro de Van Gogh representa, a partir do processo de mimese, um vaso de girassóis, amostras podem representar uma população no sentido estatístico, além de procedimentos de escolha por mérito. Contudo, a visão de representação neste trabalho perpassa a ideia de representação política não eleitoral autorizada pelos representados. A representação, prossegue, "[...] é um fenômeno primário, fundante da própria política. Nas disputas políticas, as pessoas buscam falar em nome de outros, isto é, colocam-se na posição de representantes." (MIGUEL, 2014, p. 27). 


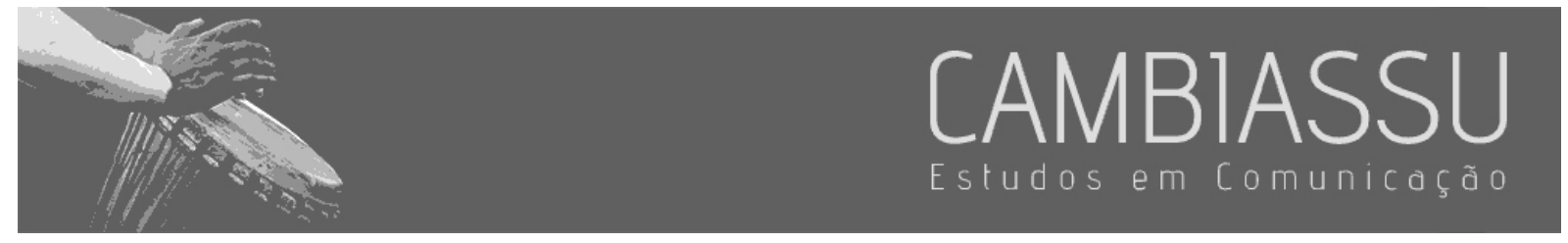

Consideramos a ideia de representação política como advocacy — prática política que tem a finalidade de interferir no ciclo de políticas públicas, orientada por indivíduos ou organizações sociais. De acordo com Bonamusa e Villar (1998), o conceito de advocacy está ligado à promoção, defesa ou argumentação de uma causa ou demanda. Essa prática contribui para que ações políticas sejam mais efetivas.

Para Urbinati (2000), advogar uma causa ou posicionamento não prescinde de partidarismo exacerbado e a ação dos advocates garante benefícios aos representados por permitir que os seus interesses sejam promovidos de forma efetiva - justamente por conta da expertise que carregam como profissionais da ação política. Os advocates, assevera, se configuram como defensores apaixonados, inteligentes e capacitados para compreender os argumentos alheios (URBINATI, 2000).

Miguel (2014) afirma que é cada vez maior a quantidade de intermediários na relação que deveria se estabelecer entre o Estado e a sociedade civil. Eles são admitidos como interlocutores legítimos e representantes de interesses de grupos. Organizações da sociedade civil e organizações não-governamentais atuam como representantes, mas ele questiona se estas formas de representação são democráticas.

A participação de organizações com estratégias de advocacy em esferas de debate e deliberação pode ser considerada como representativa porque assimila demandas de grupos que estariam silenciadas. Mas esse mesmo caráter representativo, alerta Miguel (2014), apresenta déficits democráticos, como a ausência de interlocução entre representantes e representados. Os discursos colocados em circulação e componentes do livre debate público deveriam ser validados "[...] a partir de uma troca efetiva com uma base." (MIGUEL, 2014, p. 256).

Miguel (2014) também chama a atenção para a legitimidade dos intermediários. A posição de porta-voz de determinados interesses sociais pode ser almejada por diversos grupos e organizações, mas a legitimidade de se colocar na esfera pública depende da capacidade de agir. "A contraface da 


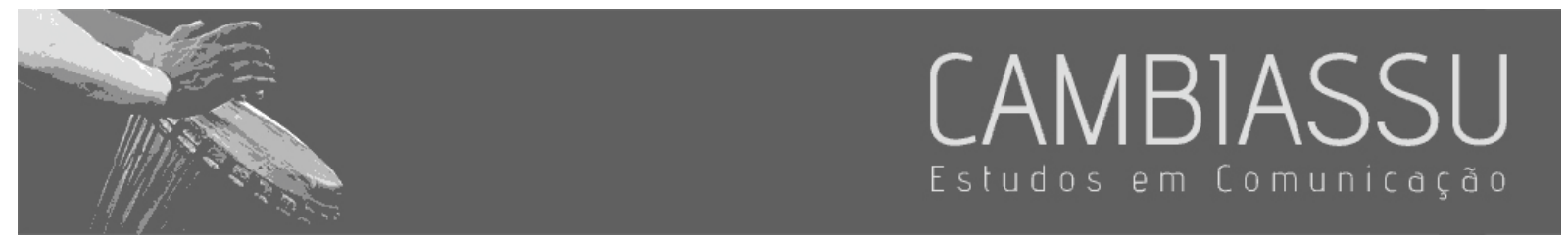

capacidade de agir é o reconhecimento como interlocutor válido [...]", aponta o autor, ao complementar que alguém o provê: "[...] alguém reconhece que determinada organização está credenciada a falar em nome de determinados grupos, experiências ou interesses." (MIGUEL, 2014, p. 259). Dessa forma, o Estado é quem convoca esses representantes para os espaços de negociação.

Além da convocação para lugares de fala, de acordo com Miguel (2014), a adaptação aos modos discursivos dominantes é fator importante para geração de legitimidade. Ele ressalta neste processo que a centralidade de "determinada modulação de fala" e uma recusa a esses padrões podem implicar em marginalização: "[...] o padrão discursivo é um poderoso mecanismo de exclusão e de conformidade ao campo." (MIGUEL, 2014, p. 260).

\section{Identificação de demandas e organização da comunicação}

Lycarião (2010, p. 65-66) aponta que a tarefa de produção e distribuição de conteúdos que alimentem debates públicos tem se tornado mais dinâmica diante das possibilidades oferecidas pela evolução dos meios digitais: "[...] a internet poderia estar permitindo uma ampliação do sistema informativo de modo mais eficiente do que as condições anteriores permitiam". Diante desta lógica, a rede social Facebook tem ganhado cada vez mais relevância como instrumento de visibilidade e interação de movimentos sociais em todo o mundo.

Criado em 2004, o Facebook é uma das redes sociais que mais cresceu na última década. Importante rede de relacionamentos em geral nos principais aglomerados urbanos do mundo, reúne aproximadamente um bilhão de usuários ativos e se destaca como um importante espaço de interação social na internet. No Brasil, ganhou a preferência do público a partir de 2011 e atualmente tem 100 milhões de contas ativas no País (FACEBOOK, 2017).

A dinâmica de timeline agrupa as postagens de indivíduos e fanpages seguidas por cada usuário, que pode interagir com as mensagens com comentários, compartilhamentos e curtidas. A 


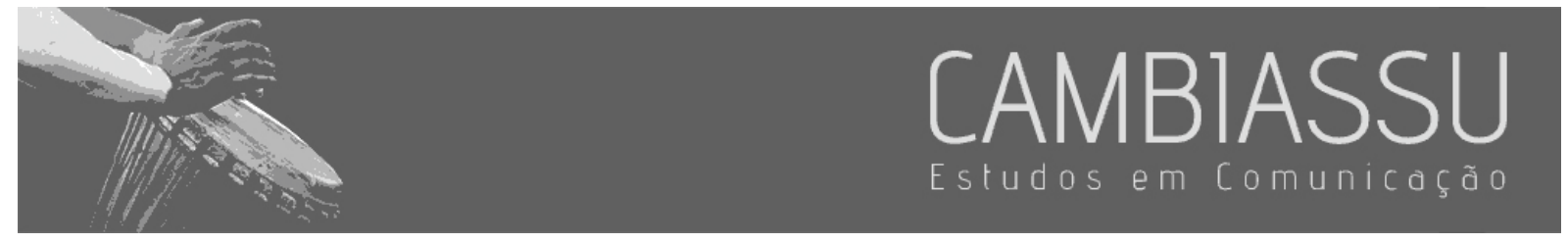

publicação de conteúdos evoluiu desde a liberação da rede social em grande escala: publicação de imagens e vídeos, possibilidade de chamadas de vídeo pela internet, troca de mensagens, formação de fóruns e grupos fechados, transmissão de eventos ao vivo, criação de agendas, entre outros (FACEBOOK, 2017).

O universo do Facebook abriga dezenas de páginas pessoais ou fanpages de organizações que se apresentam como debatedoras de temas relacionados à questão indígena no Brasil. O processo de escolha para a concentração da análise foi iniciado com um mapeamento de movimentos sociais indígenas da região Amazônica que atuam nas redes sociais. Na primeira etapa, fanpages no Facebook foram identificadas a partir das palavras-chave "movimentos", "movimentos sociais" e "indígenas".

Este processo permitiu a identificação de dezenas de páginas de associações e outras organizações civis representantes de diversos povos indígenas. No entanto, foram escolhidos os movimentos Mobilização Nacional Indígena (MNI), por ser criado e comandado por indígenas, e Conselho Indigenista Missionário (CIMI), pela ligação com a Igreja Católica e atuação histórica como porta-voz de indígenas.

A seguir, apresentamos um perfil das organizações:

\section{- Mobilização Nacional Indígena (MNI)}

Site institucional: <www.mobilizacaonacionalindigena.wordpress.com>.

Fanpage no Facebook: <www.facebook.com/mnindigena>.

Número de curtidas: 75.294

Número de seguidores: 76.528 .

\section{- Conselho Indigenista Missionário (CIMI)}

Site institucional: <www.cimi.org.br>. 


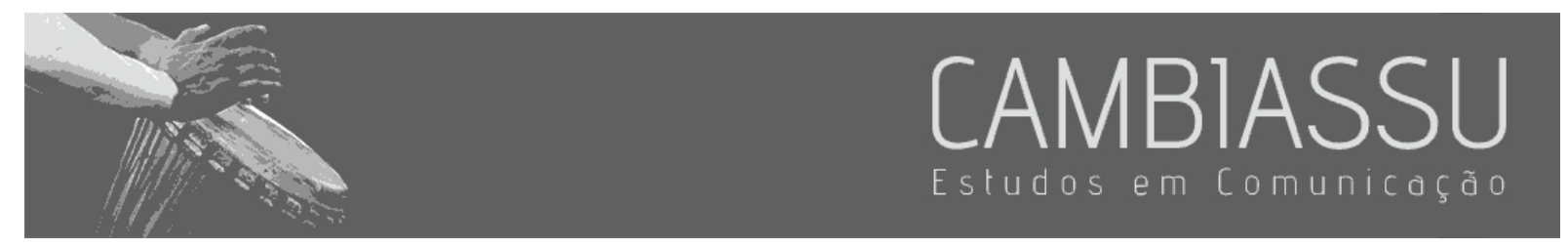

Fanpage no Facebook: <www.facebook.com/conselhoindigenistamissionario>.

Número de curtidas: 71.450 .

Número de seguidores: 71.740 .

O ambiente digital proporcionado pela rede social prescinde de relações de trocas de informação e possibilita interação multimídia em tempo real, com possibilidade de compartilhamento, mas, sobretudo, é locus de construção de linguagens, como meio de comunicação. Essa posição, destacam Garcêz e Maia (2016, p. 14), possibilita "[...] a visibilidade de novas perspectivas em cena, apresentadas por meio de vários modos comunicativos." - além da "[...] inclusividade de novos atores e o papel dos meios de comunicação nesse cenário".

Essa vertente da representação política tem sido debatida por pesquisadores como Saward (2010), que coloca esse caráter discursivo como central: parte do ponto de vista de que grupos ou demandas não podem ser representados de forma total. O que se representa, de fato, são discursos. Dessa forma, ao avaliar a produção de conteúdos por grupos que representam indígenas no Facebook, pretendemos compreender elementos do processo de advocacy e identificar quais são e como são colocadas as demandas de representação (representative claim) entre os meses de agosto e novembro de 2017 - especificamente durante 92 dias —, marcados pela discussão sobre a política de demarcação de terras indígenas e gerenciamento da Fundação Nacional do Índio (Funai) no governo do presidente Michel Temer (PMDB).

Para avaliar a produção de conteúdos de organizações que representam grupos indígenas no Facebook, optamos pela análise de conteúdo como instrumento metodológico de observação e interpretação de aspectos sociais e conteúdos ideológicos de textos e imagens (BARDIN, 1977; BAUER; GASKELL, 2003). "A intenção da análise de conteúdo é a inferência de conhecimentos 


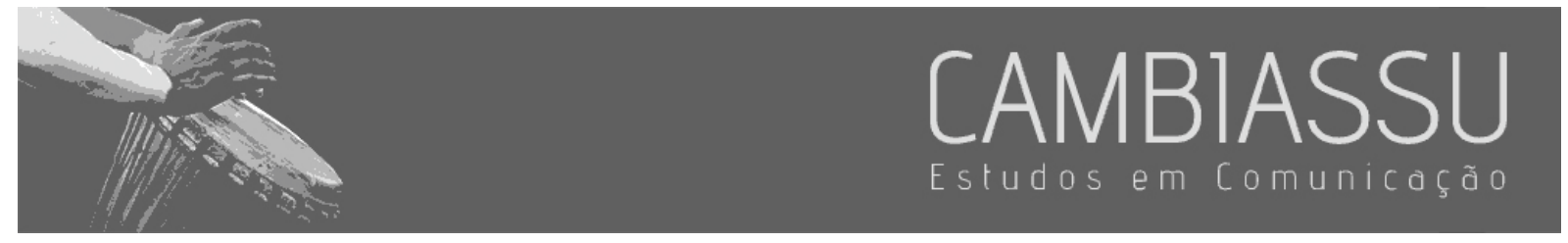

relativos às condições de produção (ou, eventualmente, de recepção), inferência esta que recorre a indicadores (quantitativos ou não)." (BARDIN, 1977, p. 38).

A coleta de materiais para a análise de conteúdo foi realizada com auxílio do software Netlytic, que possibilita o mapeamento de redes sociais como o Facebook, com captura de informações de postagens e comentários e geração de dados relacionados a tópicos populares, a temas de discussões e a gráficos. O percurso de análise começa com a importação de registros de fanpages para a elaboração do conjunto de dados (dataset), que será analisado, oferecendo, dentro do período escolhido, os links, datas, autoria, textos e frequência de posts (considerando postagens e comentários). Na segunda etapa, o Netlytic apresenta análise textual. O extrator de palavras-chave permite a visualização de uma nuvem de palavras, que lista os termos mais recorrentes nas postagens. Na terceira etapa, a análise de rede (network), o software gera a representação gráfica do conjunto de nós conectados (clusters), nós (nodes) e laços (edges).

A análise de conteúdo serve de base para a identificação de elementos da cultura da comunicação on-line proposto por Kavada (2013), que divide organizações e estratégias a partir de características horizontais, marcadas pela interatividade e verticais, voltadas a transmissões de informação em larga escala. De acordo com Oliveira (2017), autora de pesquisa que caracterizou atores de movimentos sociais negros na internet, a tipologia de Kavada permite criar caminhos para o entendimento sobre a natureza das razões que levam grupos a utilizar tecnologias digitais e redes sociais.

Oliveira (2017, p. 63) destaca oito elementos da cultura de comunicação on-line apresentados por Kavada: conteúdo, forma, fins e função de comunicação; infraestrutura comunicacional; produção de conteúdo; processo e distribuição e publicação/endereçamento público; fluxos de comunicação; além de relações, papéis e responsabilidades sociais. A partir desses pontos, considera a cultura horizontal como processo ligado a lutas e mobilizações, com possibilidade de colaboração, foco na 


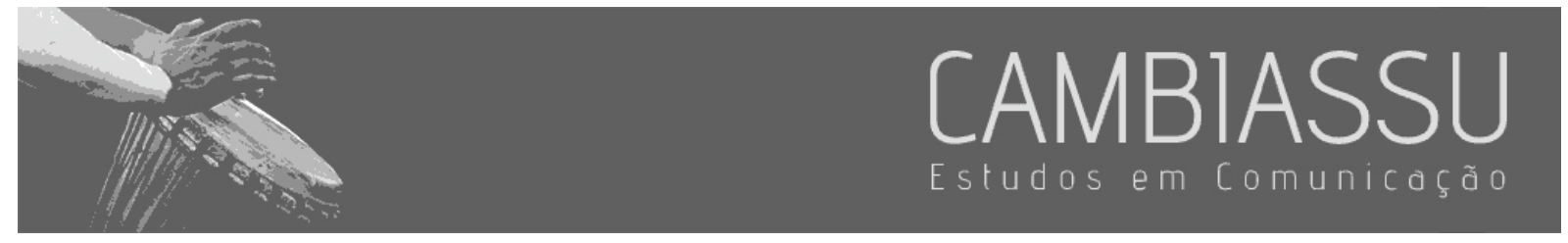

audiência interna e produção de conteúdos não centralizada e não profissional. Já a cultura horizontal apresenta características de broadcasting, com oferecimento de informações factuais e chamamentos a eventos, sem permissão de colaboração, produção profissional e com foco na audiência externa e estratégias do ator.

\section{Demandas e características da comunicação da mni}

A Mobilização Nacional Indígena (MNI) consiste em elemento central do plano de ação institucional da Articulação dos Povos Indígenas do Brasil (APIB) — associação nacional de entidades que representam povos indígenas de várias regiões do Brasil -, com deliberações anuais que envolvem em média cerca de mil lideranças indígenas no Acampamento Terra Livre (ATL), na Esplanada dos Ministérios, em Brasília - DF. As deliberações do ATL, instância superior da APIB, são reverberadas pela mobilização nacional nos períodos subsequentes, com destaque para a identificação de problemas e definição de demandas e reivindicações dos povos indígenas representados. A MNI tem aproximação com coletivos de produção de conteúdos independentes, como o Mídia Índia, Jornalistas Livres e Mídia Ninja.

A atuação da MNI na internet está concentrada na fanpage da iniciativa no Facebook, apesar da existência de um blog com informações básicas sobre os objetivos e ações. No período analisado, as principais demandas identificadas estão relacionadas à demarcação de terras indígenas, às garantias de direitos de povos indígenas e à campanha contrária ao marco temporal. Os termos mais citados são "indígenas", "povos", "direitos", "demarcação", "terras" e "marco temporal".

A nuvem de palavras mais recorrentes nas 346 postagens registradas indica o modo de atuação da MNI, com palavras-chave ligadas a objetivos das ações: "articulação", "assembleias", "audiência", "campanha", "mobilização" e "comissão". Mostra, inclusive, as principais instâncias às 


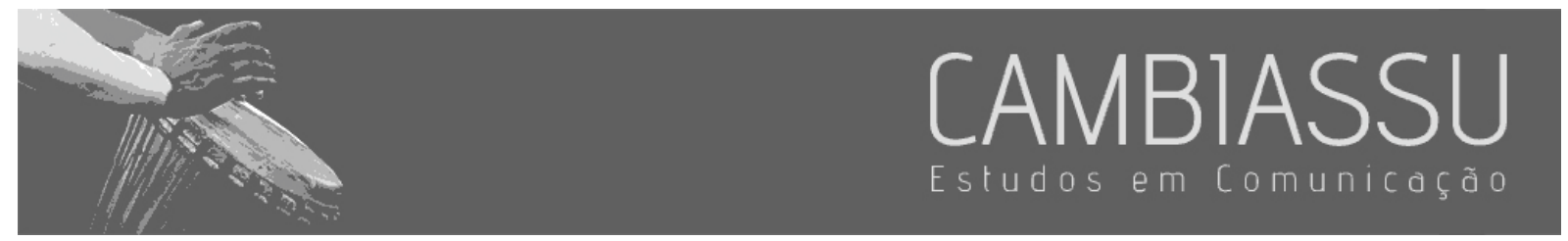

quais a entidade recorre: Fundação Nacional do Índio (Funai), Ministério da Justiça e Supremo Tribunal Federal (STF).

Apesar de a APIB congregar o movimento de povos e organizações indígenas da região Nordeste, Minas Gerais e Espírito Santo (APOINME), do Pantanal e região (Arpipan), do Sudeste (Arpinsudeste), do Sul (Arpinsul), assembleia do povo Guarani (ATY Guassú) e a Coordenação das Organizações Indígenas da Amazônia Brasileira (COIAB), as postagens da MNI seguem uma unidade discursiva na identificação do movimento, sempre com classificação geral, como "povos", "índios" e "indígenas". Seguindo o objetivo de unificar demandas e política do movimento indígena, não citam diretamente etnias ou outros grupos — salvo exceções, a exemplo de compartilhamento de postagens de outras fanpages.

A frequência de postagens no período analisado seguiu média de dez itens por dia, com três momentos de ápice, resultando em aumento de compartilhamentos e maior interação com os seguidores. No dia 16 de agosto de 2017, foram registrados 47 comentários a partir de duas postagens da MNI sobre protestos contrários ao marco temporal, com links para leitura de documentos no blog da iniciativa e compartilhamento de transmissão ao vivo de sessão no STF na qual a questão foi apreciada. A postagem da live no Facebook teve 222 compartilhamentos e 454 curtidas.

Os outros dois momentos com maior frequência de posts foram registrados nos dias 16 e 30 de maio de 2017. No primeiro, as informações eram voltadas ao andamento das Comissões Parlamentares de Inquérito (CPI) da Funai e do Instituto Nacional de Colonização Reforma Agrária (INCRA), além de protestos em Brasília e outras cidades do País em favor da demarcação de terras indígenas. No segundo, concentraram-se no debate da votação do relatório das CPls, que pediu o indiciamento de 67 pessoas, entre lideranças comunitárias, antropólogos e servidores públicos por supostos crimes cometidos durante processos de demarcação de terras indígenas. 


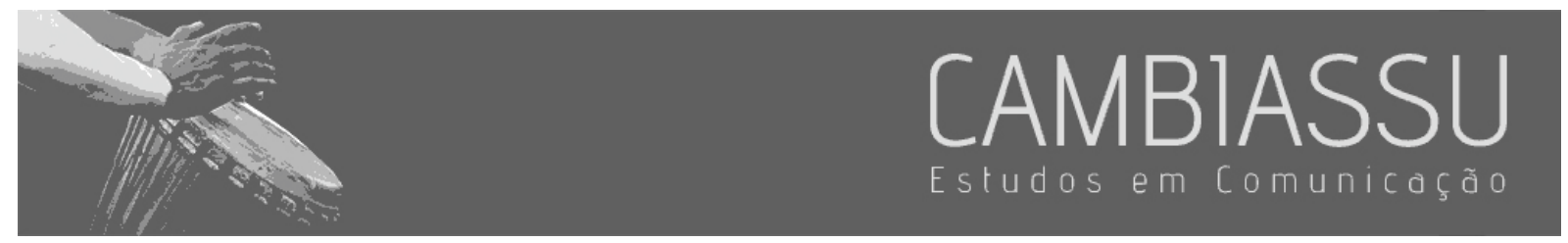

A análise de rede (network) permite uma visualização das conexões proporcionadas pela atividade da fanpage da MNI. O gráfico de clusters gerado pelo Netlytic a partir dos temas mais recorrentes nas postagens e comentários reforça como a atuação da iniciativa no Facebook influencia outros perfis a debaterem seus conteúdos-chave - que representam as demandas identificadas a partir da nuvem de palavras (RECUERO, 2009). De acordo com dados gerados pelo Netlytic, a rede em questão tem índice de centralização 0.2762 em uma escala de 0 a 1. Quanto mais próximo de 1, o software indica que os participantes centrais dominam o fluxo de informações. No caso da rede da MNI, os demais atores conectados consistem em perfis pessoais e não de organizações. Dessa forma, a classificação próxima de zero significa que as informações fluem de forma mais livre entre os participantes (NETLYTIC, 2017).

No desenho da rede, segundo Recuero (2009), os nós com o maior número de conexões aparecem no centro - aqueles que representam as demandas "marco temporal", "direitos indígenas" e "demarcação de terras indígenas". Na área periférica, localizam-se os nós com menor número de conexões, portanto, temas com menor intensidade de compartilhamento e comentários. Esse comportamento da rede reforça o caráter horizontal do uso da fanpage pela MNI considerando os elementos da cultura de comunicação on-line propostos por Kavada (2013). O conteúdo apresentado é sobretudo relacionado a informações ligadas a demandas indígenas — em ações contrárias ao Marco Temporal e CPIs da Funai e Incra —, apresentação de eventos para discussão e mobilização para encontros de diversos povos representados pela iniciativa ou para atuação em espaços de deliberação, como o Senado Federal, inclusive com transmissão ao vivo.

Entre fins e funções de comunicação, foi identificada a busca por conscientização e mobilização em torno do objetivo maior, de defender as demandas coletivas, de acordo com as definições do Acampamento Terra Livre. A audiência é classificada como mista, de natureza interna, mas que abrange 76.528 seguidores. No período analisado, não foram publicados na fanpage conteúdos 


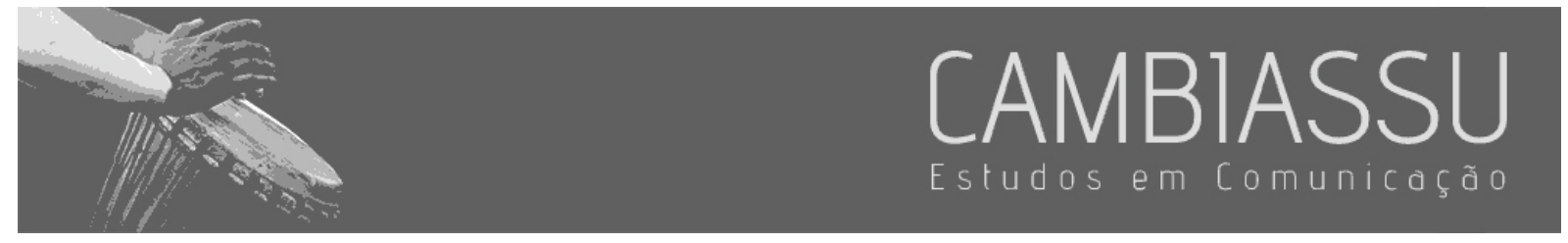

próprios com base audiovisual, produção artística/publicitária ou informações trabalhadas com estrutura jornalística.

A forma apresenta caráter colaborativo, com forte utilização dos recursos de compartilhamento de conteúdos de outros perfis, mas não possui características de planejamento prévio de divulgação ou uso de métricas para postagem no Facebook. A fanpage da MNI utiliza de forma recorrente o recurso de compartilhar conteúdos produzidos por outras organizações, realizados em parceria ou não, como coberturas on-line e vídeos de protestos ou eventos de associações ou comunidades indígenas, gravados pelos grupos Mídia Ninja, Jornalistas Livres, Mídia Índia, Comissão Guarani e CIMI.

\section{Demandas e características da comunicação do ClMI}

O Conselho Indigenista Missionário é o braço de atuação da Conferência Nacional dos Bispos do Brasil (CNBB) para contato da Igreja Católica com indígenas. Criado em 1972, o órgão tem como principal objetivo articular lideranças de povos e aldeias para garantir o reforço da causa indígena e de mobilizações pela garantia dos direitos históricos. A atuação do CIMI se desenvolve em 11 unidades regionais, sendo que quatro delas têm foco na região amazônica. O conselho tem papel importante na reverberação de demandas indígenas no País, notadamente no processo de construção da usina hidrelétrica de Belo Monte, que provocou impacto direto em terras indígenas na região de Altamira, no Pará.

O CIMI está presente na internet com perfis em outras redes sociais além do Facebook e site institucional, que tem a função de repositório de conteúdos citados nas postagens, como textos de assessoria de imprensa, relatórios e outros documentos. No período analisado, as principais demandas identificadas dizem respeito a direitos humanos, direitos dos povos indígenas, demarcação de terras indígenas e gestão da Funai. Os termos mais citados são "indígenas", "indígena”, "direitos”, "humanos", "povos", "terra/terras", "demarcação" e "Funai". 


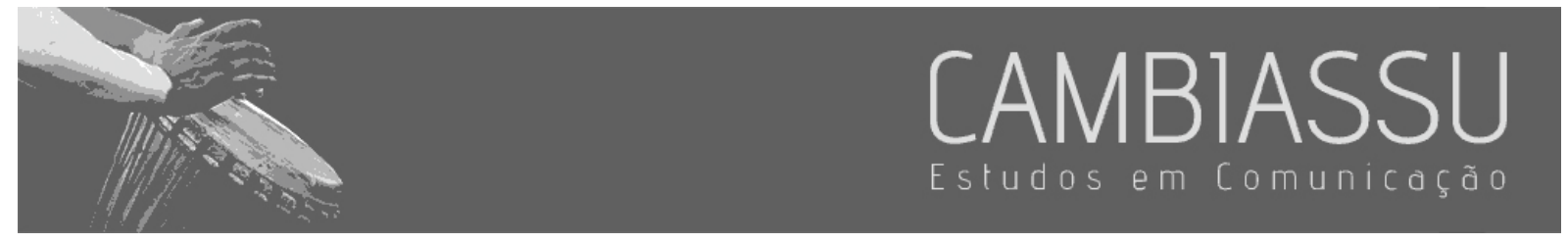

A nuvem de palavras mais recorrentes nas 462 postagens registradas indica o caminho das discussões mais tratadas pelo CIMI em suas ações estratégicas junto a grupos indígenas e ao Poder Público: “assembleia”, “audiência”, “bancada”, ‘Brasília”, "governo”, “MPF” (Ministério Público Federal), “organizações" e "relatórios". Entre as palavras mais citadas está também o termo "CIMl", que remete à autorreferência e à divulgação de eventos promovidos pelo conselho.

A frequência de postagens no período analisado seguiu média de 15 itens por dia. Houve três momentos de maior interação com os seguidores e compartilhamentos. O ápice ocorreu no dia 18 de outubro de 2017, quando o CIMI fez postagem com vídeo mostrando o protesto de grupos indígenas impedidos de ingressar em debate sobre agricultura indígena na Comissão de Agricultura, Pecuária, Abastecimento e Desenvolvimento Rural da Câmara dos Deputados, em Brasília. O vídeo que mostrava indígenas em confronto com seguranças alcançou 119 mil visualizações, 5.456 compartilhamentos, 1,3 mil curtidas e 163 comentários.

O segundo momento de maior interação ocorreu no dia 5 de outubro de 2017, com a postagem de link para texto produzido pela assessoria de imprensa do CIMI e acesso ao relatório "Violência contra os povos indígenas do Brasil - Dados de 2016. No terceiro momento, no dia 13 de setembro, foram destacadas notícias institucionais sobre a retirada de posseiros que ocupavam $20 \%$ da Terra Indígena Pankararu, no sertão de Pernambuco.

A análise de rede (network) da fanpage do CIMI a partir do gráfico de clusters gerado pelo Netlytic mostra estrutura semelhante à da MNI. A iniciativa do conselho no Facebook influencia o debate de seus conteúdos-chave por outros perfis. De acordo com dados do Netlytic, a rede formada pela atuação da fanpage tem índice de centralização 0.3943 em uma escala de 0 a 1 . O afastamento do ponto zero indica maior tendência de domínio do fluxo de informações pelo participante central, apesar de, no caso da rede do CIMl, os demais atores conectados consistirem em perfis pessoais. Assim, o 


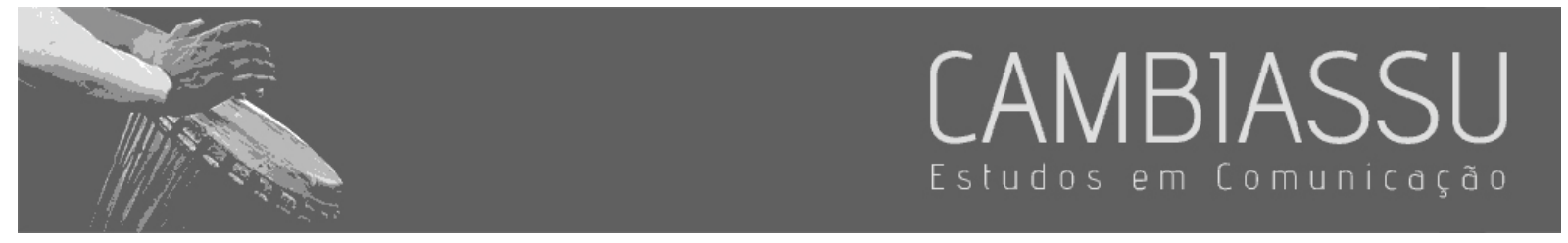

índice registrado indica tendência de fluxo de informações com menor liberdade entre os participantes (NETLYTIC, 2017).

Apesar de o índice de centralização não ter se aproximado de 1, o comportamento da rede do CIMI mostra tendência de caráter vertical no uso da fanpage, considerando os elementos da cultura de comunicação on-line propostos por Kavada (2013). O conteúdo apresentado se destina à divulgação de eventos realizados pelo conselho e informações gerais sobre a atuação da organização. Em relação à forma, os links levam sempre ao site institucional e os vídeos publicados sobre projetos têm assinaturas com a logomarca do CIMI. A fanpage transmite eventos institucionais e de órgãos do Poder Público, como sessões parlamentares, ao vivo, mas não compartilha conteúdos citando diretamente os perfis de origem.

Considerando os fins e funções de comunicação, as informações factuais sobre convocações para eventos e resultados de ações do CIMI são divulgadas com direcionamento para textos produzidos pela assessoria de imprensa. Temas relacionados à mobilização são direcionados de acordo com as estratégias da organização. A fanpage, que abrange 71.450 seguidores, publica somente conteúdos do CIMI. A maioria com estrutura formal e apoio de texto base produzido pela equipe própria. O foco apresenta características externas.

\section{Considerações finais}

A análise das fanpages no Facebook de organizações que se colocam como representantes de demandas de povos ou organizações indígenas permite a identificação do formato das redes e articulações com outros atores sociais. Nos dois casos, de acordo com os grafos gerados pelo Netlytic, são redes que permitem o fluxo livre de informações entre os participantes - em maioria perfis pessoais e não de organizações. No entanto, na comparação do índice de centralidade, a fanpage do CIMI tem maior tendência a centralizar o fluxo de informações do que a da MNI. 


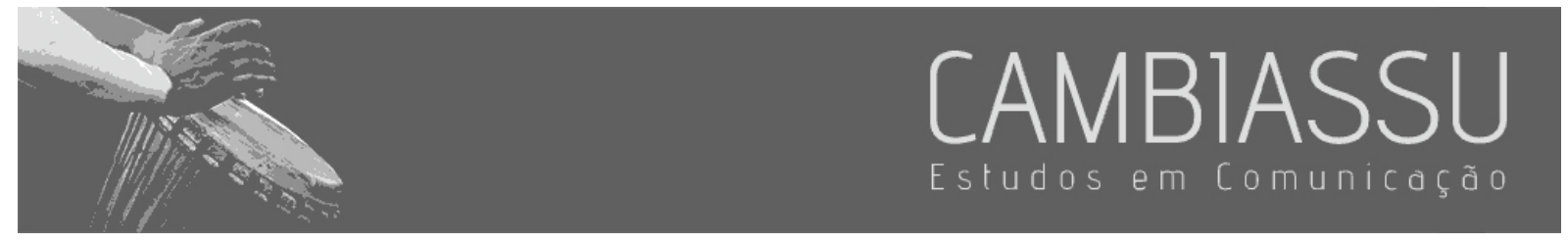

Esse dado é importante porque reforça a diferenciação das fanpages em relação à cultura da comunicação on-line. Enquanto a fanpage da MNI apresenta características horizontais, com destaque para a publicação de conteúdos a partir de compartilhamentos diretos e colaborações, a página do CIMI tem estrutura vertical, com produção centralizada e relacionada às ações da organização. As diferenças de abordagem alimentam a discussão sobre o acesso dos representados a esses sistemas e quem fala em nome de quem.

As fanpages dão visibilidade a demandas semelhantes, como a demarcação de terras indígenas e outros direitos, mas a natureza discursiva da representação dessas demandas exige estudo aprofundado sobre o conteúdo das postagens, considerando os fins e funções da comunicação e capacidade real de mobilização em busca de produção de consensos. No entanto, os resultados abrem perspectivas para a análise de outras estratégias dentro de relações de advocacy na representação política não eleitoral.

\section{Referências}

BARDIN, L. Análise de conteúdo. Lisboa: Edições 70, 1977.

BAUER, M; GASKELL, G. Pesquisa qualitativa com texto, imagem e som. Petrópolis: Vozes, 2003.

BONAMUSA, M; VILLAR, R. Estructura de oportunidades políticas y advocacy: elementos para un modelo político dei tercer sector. In: Primer Encuentro de la Red de Investidaciones del Tercer Sector en América Latina, abril de 1998, Rio de Janeiro.

CASTELLS, M. Redes de indignação e esperança. Movimentos sociais na era da internet. Rio de Janeiro: Zahar, 2013.

CASTELLS, M. O poder da comunicação. Rio de Janeiro/São Paulo: Paz e Terra, 2015.

FACEBOOK. Central de Ajuda, 2017. Disponível em: ttps://www.facebook.com/help/feedback. Acesso em: 20 de nov. 2017.

GARCÊZ, Regiane; MAIA, Rousiley. Representação política não-eleitoral em uma perspectiva processual: discursividade e estratégia no debate sobre a educação de surdos. Revista Compolítica, Rio de Janeiro, v. 6, n. 2, p.7-34, jan./jul. 2016. Disponível em: http://compolitica.org/revista/index.php/revista/article/view/103. Acesso em: 01 jun. 2017.

GOMES, Wilson. A política na timeline - Crônicas de Comunicação e Política Em Redes Sociais Digitais. Salvador: EDUFBA, 2014. 


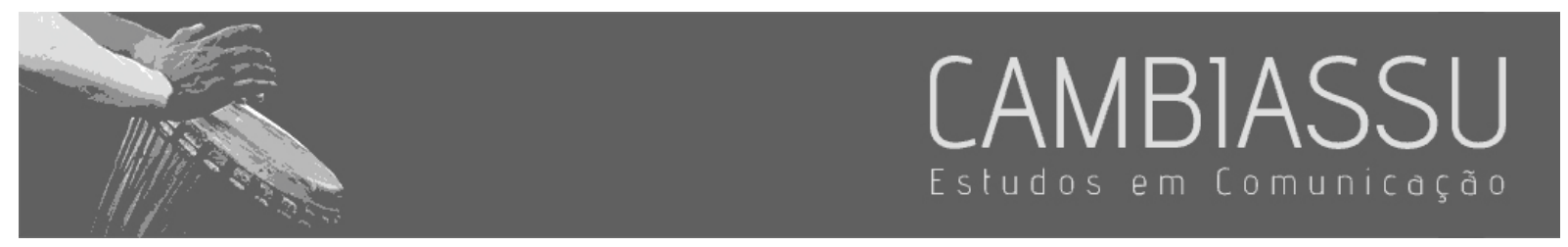

KAVADA, Anastasia. Internet cultures and protest movements: the cultural links between strategy, organizing and online communication. In: CAMMAERTS, Bart; MATTONI, Alice; McCURDY, Patrick (Ed). Mediation and Protest Movements. Bristol; Chicago: Intellect, 2013.

LYCARIÃO, Diógenes. Greenpeace, espetáculo e internet: o intercruzamento entre diferentes modos de comunicação para se sustentar debates na esfera pública. 2010. 150 f. Dissertação (Mestrado em Comunicação Social) - Programa de Pós-Graduação em Comunicação Social da UFMG, Belo Horizonte, 2010.

MAIA, R. Redes cívicas e internet: efeitos democráticos do associativismo. In: GOMES, W. e MAIA, R. Comunicação e democracia. Problemas e perspectivas. São Paulo: Paulus, 2008.

MENDONÇA, Ricardo Fabrino. Comunicação e sociedade civil: interfaces e agendas. Revista Compolítica, v. 1, p. 8-44, 2011. Disponível em http://compolitica.org/revista/index.php/revista/article/view/4/2. Acesso em: $26 \mathrm{dez}$. 2016.

MIGUEL, Luis Felipe. Democracia e representação. Territórios em disputa. São Paulo: Editora Unesp, 2014.

NETLYTIC. Network Analysis/Visualization, 2017. Disponível em: https://netlytic.org/home/?page_id=2. Acesso em: 20 de nov. 2017.

OLIVEIRA, Alicianne. Representação política e movimentos sociais negros no Brasil: um estudo sobre as experiências de comunicação on-line de ativistas e entidades. 2017. 199 f. Tese (Doutorado em Comunicação Social) - Programa de Pós-Graduação em Comunicação Social da UFMG, Belo Horizonte, 2017.

RECUERO, R. Redes sociais na Internet. Porto Alegre: Sulina, 2009.

SAWARD, Michael. The Representative Claim. Oxford: Oxford University Press, 2010.

URBINATI, Nadia. Representation as Advocacy: a Study of Democratic Deliberation. Political Theory, [S.I.], v.28, n.6, p.758-86, 2000. 